\title{
Tensile behaviour of FRC under high strain-rate
}

\author{
Ezio Cadoni - Alberto Meda - Giovanni A. Plizzari
}

Received: 7 November 2007/Accepted: 11 June 2009/Published online: 31 July 2009

(C) RILEM 2009

\begin{abstract}
This paper presents experimental results on two types of concrete reinforced with steel and polyvinyl-alcohol (PVA) fibres subjected to dynamic tensile loading. The tests were carried out by using a Modified Hopkinson Bar apparatus on fibre reinforced concrete notched-specimens under three different strain-rates $\left(50,100\right.$, and $\left.200 \mathrm{~s}^{-1}\right)$. From the experiments it was found that there is a significant enhancement in tensile strength with increasing strain-rates. The dynamic tests on steel FRC with the smaller loading rate $\left(50 \mathrm{~s}^{-1}\right)$ showed a strength similar to the one measured from static tests; however, for increasing loading rates, a remarkable decrease of post-peak strength and ductility occurs. In specimens with PVA fibres, an enhancement of the tensile strength was also observed and a significant reduction of fracture energy and ultimate deformation occurred. Some experimental aspects are also discussed as the specimen shape, its dimension, the
\end{abstract}

E. Cadoni $(\square)$

Department of Environment, Constructions and Design, University of Applied Sciences of Southern Switzerland, Lugano, Switzerland

e-mail: ezio.cadoni@supsi.ch

\section{A. Meda}

Department of Engineering Design and Technologies, University of Bergamo, Bergamo, Italy

\section{G. A. Plizzari}

Department of Civil Engineering, Architecture, Land and Environment, University of Brescia, Brescia, Italy loading rate as well as the different post-peak behaviour from static and dynamic tests.

Keywords FRC $\cdot$ High strain-rate $\cdot$ Tensile tests · Dynamic tests $\cdot$ High performance concrete

\section{Introduction}

The use of fibre reinforced concrete (FRC) has been continuously increasing during the last years because of its enhanced performances in terms of toughness and crack control. As a consequence, FRC is now widely used for industrial pavements, in small prefabricated elements, in shotcrete and, recently, has been adopted also for the final lining in conventional or segmental tunnels [1].

The great development of FRC and its application in structural engineering encouraged the development of newer high performance materials for further structural applications and/or special loading cases. Among these loading cases, because of the worldwide growing concern for terrorist attacks against civilian targets, the need to better understand the impact resistance of FRC and how to enhance its performances comes up [2].

The effects of high loading rates on FRC are also an important requirements for the design of special types of structures as tower buildings, off-shore, sheltering structures or nuclear plants. In fact, during 
their lifetime, these structures could be subjected to high strain-rates produced by impact loads or blast; under all these loading conditions, the enhanced toughness of FRC seems a promising answer to structural requirements [3-5].

In the present paper, experimental results from a research program focused on the mechanical characteristics in tension under high strain-rates are described. Two types of FRC were considered, the first one was reinforced with steel fibres (S-FRC) while the second one was reinforced with polyvinylalcohol fibres (PVA-FRC).

The high strain-rate behaviour of FRC specimens was studied by means of a modified Hopkinson bar (MHB). In the discussion, some experimental aspects as the specimen shape, dimension, the loading rate as well as the different post-peak behaviour in static and dynamic tests are considered; consequently, the experimental results allow for a better choice of the type of fibre required to enhance FRC ductility under dynamic loads.

\section{Materials}

Both static and impact tests were performed on specimens made of a very high strength concrete matrix having maximum aggregate size of $1.3 \mathrm{~mm}$ in addition to $1000 \mathrm{~kg} / \mathrm{m}^{3}$ of cementitious materials (cm) with a water $/ \mathrm{cm}$ ratio of 0.17 . The concrete matrix was initially designed for including a volume fraction $\left(V_{\mathrm{f}}\right)$ of $2.5 \%$ (corresponding to $196 \mathrm{~kg} / \mathrm{m}^{3}$ ) of steel fibres having a length of $18 \mathrm{~mm}$ and a diameter of $0.15 \mathrm{~mm}$. The same concrete matrix was also used for the same volume fraction $(2.5 \%$, corresponding to $22.5 \mathrm{~kg} / \mathrm{m}^{3}$ ) of PVA fibres, having a length of $12 \mathrm{~mm}$ and a diameter of $0.018 \mathrm{~mm}$.

The specimens were tested after 14 days of curing in a fog room having a temperature of $20 \pm 2^{\circ} \mathrm{C}$ and a humidity of $90 \pm 5 \%$. The compressive strength was been measured from cylindrical specimens having a diameter $(d)$ and a height $(h)$ of $70 \mathrm{~mm}$.

\section{Static tests}

The tensile behaviour under static loads was studied by using three different test set-ups [6], summarized in the following:
- uniaxial tensile tests on dog-bone un-notched specimens whose dimensions are shown in Fig. 1a. This test set-up is usually adopted for the characterization of hardening materials. The specimen ends were fixed in the hydraulic clamps by using a low pressure in order to avoid any specimen damage; in addition, neoprene sheets were placed between the specimen ends and the clamps in order to better distribute the load pressure. Two LVDTs having a gauge length of $80 \mathrm{~mm}$ were used to measure the deformation on the thinner central part of the specimen. The average strain in the thinner part was determined as the average displacement (of the two LVDTs) divided by the gauge length (Fig. 1a);

- uniaxial tensile tests with freely rotating platens on prismatic specimens $(100 \times 200 \times 40 \mathrm{~mm})$ having a notch with a depth of $35 \mathrm{~mm}$ and a width of $4 \mathrm{~mm}$ (Fig. 1b). The free rotation of the platens was obtained by means of two spherical hinges placed at $150 \mathrm{~mm}$ from the glued surface that allowed to localize the centre of rotation at the specimen ends. Four LVDTs with a base length of $45 \mathrm{~mm}$ were placed across the notched section to evaluate the relative displacement and rotation of the sections at each side of the crack surface. The average measure of the two LVDTs, placed astride the notch, was assumed as crack tip opening displacement (CTOD);

- bending tests (four-point loading) on specimens having the same crack surface of the uniaxial tensile tests. The notched beams have a size of $100 \times 320 \times 40 \mathrm{~mm}$ (the same notch of the uniaxial tensile tests) and were tested with a span length of $300 \mathrm{~mm}$ and a distance between the load points of $100 \mathrm{~mm}$ (Fig. 1c). Three LVDTs were used to measure the vertical displacement at mid-span and under the load points while two LVDTs were placed at the notch tip to measure the CTOD. Furthermore, a clip gauge was placed across the notch to measure the crack mouth opening displacement (Fig. 1c).

The main experimental results from static tests are summarized in Fig. 2 and in Table 1 in terms of nominal stress (load/cross-sectional in pure tension or moment/bending modulus) versus crack opening displacement (COD) or CTOD. All the results show the remarkably tougher behaviour provided by the 
Fig. 1 Set-up for the tensile tests: a uniaxial test on dog-bone un-notched specimens; b uniaxial test on prismatic notched specimens and $\mathbf{c}$ four point bending test on notched beams (a)
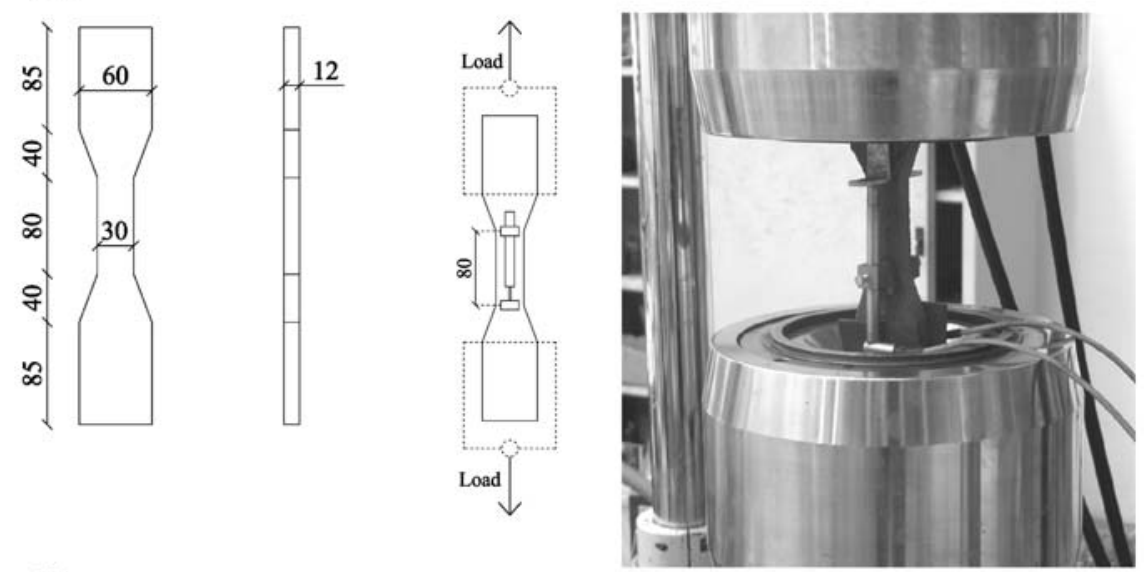

(b)
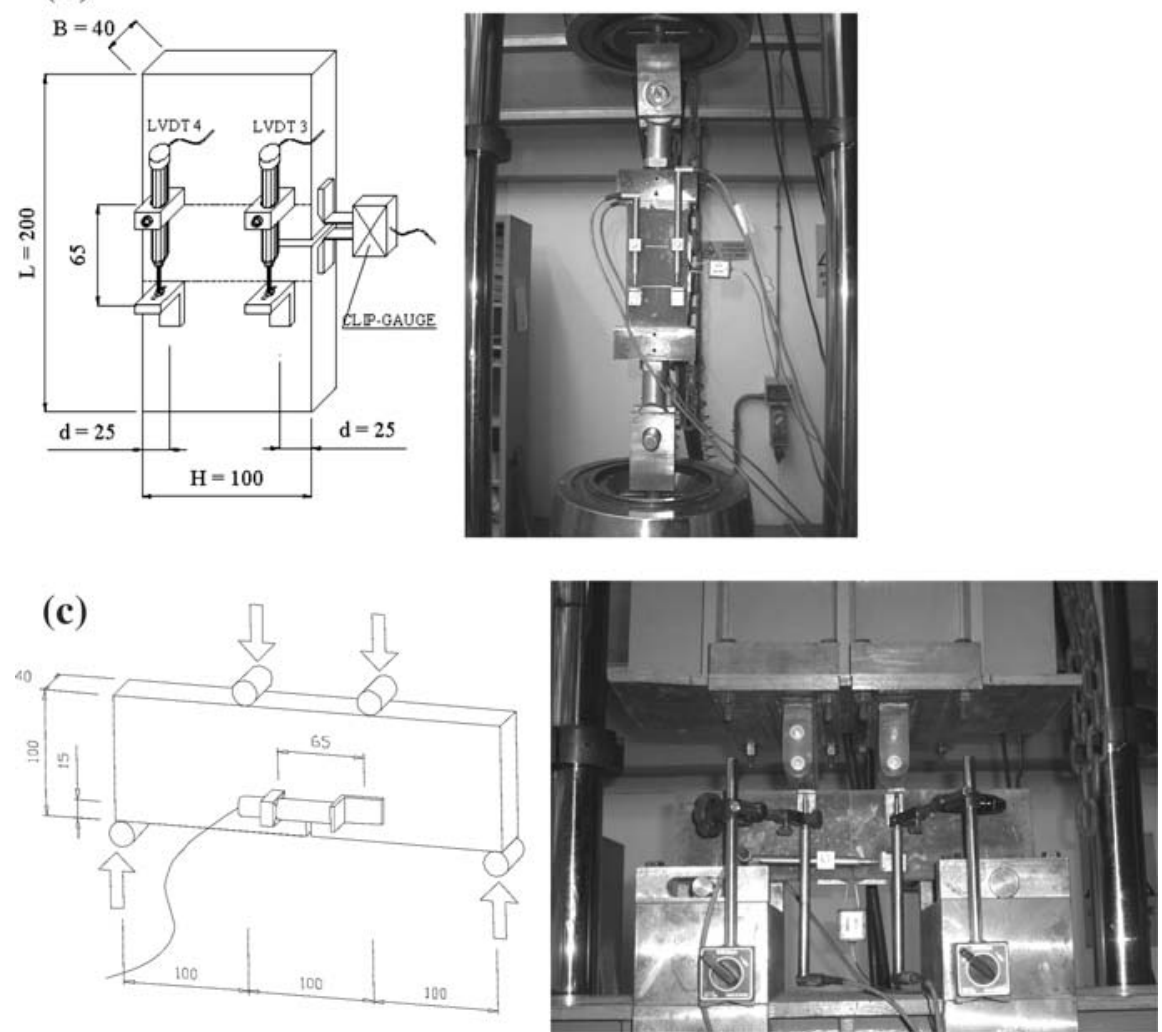

steel fibres (S-FRC) with respect to the PVA fibres (PVA-FRC).

From the uniaxial tensile test on dog-bone specimens (Fig. 2a), one can notice that, for a deformation of about 0.005 , the adopted volume fraction of PVA fibres is not longer able to control the fracture process; on the contrary, in specimens with steel fibres, after cracking the load can still increase with an hardening branch due to the development of a multicracking process (the crack onset was expected to be the same in specimens having the same concrete matrix). The maximum strength of S-FRC is nearly $80 \%$ higher than that of PVA-FRC.

The uniaxial tensile tests on notched specimens evidence a significant higher performance of S-FRC in terms of both maximum load and fracture energy (Fig. 2b). 
Fig. 2 Experimental results from tensile tests: a uniaxial test on dog-bone un-notched specimens; b uniaxial test on prismatic notched specimens; $\mathbf{c}$ four point bending test on notched beams (a)
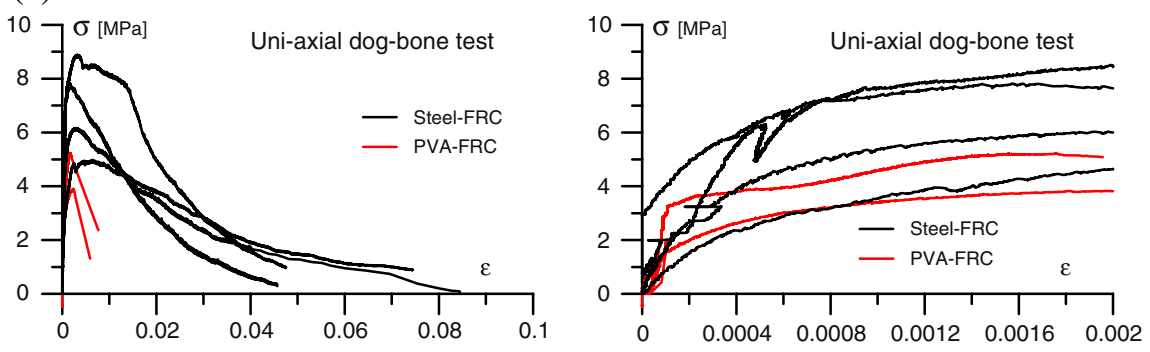

(b)
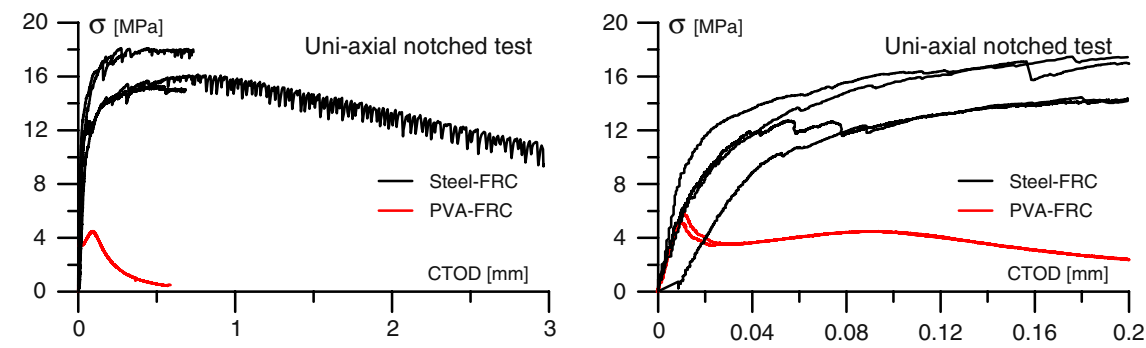

(c)

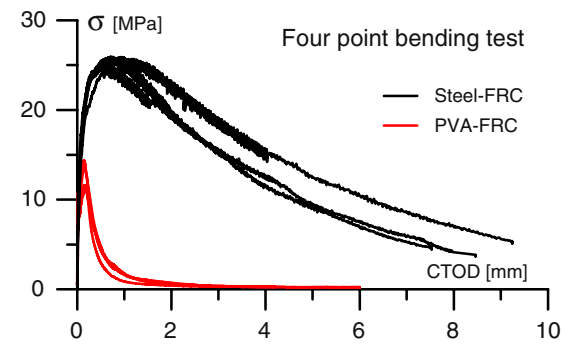

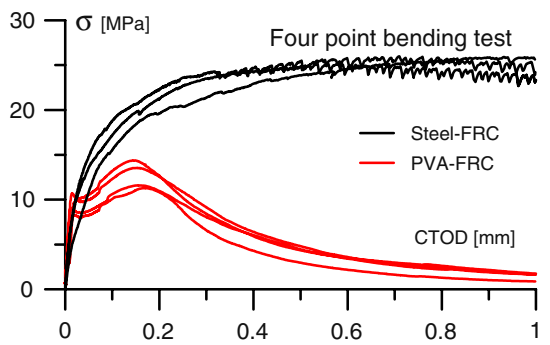

Table 1 Experimental results from static tests

\begin{tabular}{llcr}
\hline Tests & Mechanical characteristics & PVA-FRC & STEEL-FRC \\
\hline Uniaxial dog-bone test & Tensile strength $(\mathrm{MPa})$ & $3.04 \pm 0.93$ & $6.96 \pm 1.74$ \\
& Fracture energy $\left(\mathrm{J} / \mathrm{m}^{2}\right)$ & - & $14613 \pm 2620$ \\
Uniaxial notched test & Tensile strength $(\mathrm{MPa})$ & $5.24 \pm 0.14$ & $16.73 \pm 1.39$ \\
Four point bending test & Tensile strength $(\mathrm{MPa})$ & $12.70 \pm 1.49$ & $25.70 \pm 0.42$ \\
& Fracture energy $\left(\mathrm{J} / \mathrm{m}^{2}\right)$ & $1156 \pm 18$ & $16677 \pm 3409$ \\
Reference test for impact tests & Tensile strength $(\mathrm{MPa})$ & - & 5.24 \\
Compression & Compression strength $(\mathrm{MPa})$ & $161.9 \pm 5.1$ & $185.1 \pm 3.1$ \\
& Density $\left(\mathrm{kg} / \mathrm{m}^{3}\right)$ & $2233 \pm 12$ & $2427 \pm 6$ \\
\hline
\end{tabular}

The bending tests confirm the higher toughness of concrete with steel fibres; the maximum tensile strength of S-FRC is twice the one obtained from PVA-FRC (Fig. 2c). In the PVA-FRC specimens a small tensile branch develops up to a CTOD of $0.2 \mathrm{~mm}$, beyond which the contribution of PVA fibres becomes negligible. With steel fibre reinforcement, it is possible to obtain a flexural strength ranging from 25 to $30 \mathrm{MPa}$. The brittle behaviour of concrete with PVA fibres found herein is probably related to the use of a high strength concrete matrix that was originally designed for including steel fibres. 


\section{Experimental set-up for dynamic tests}

The study of the high strain-rate behaviour of the FRC materials is essential in order to better understand the actual resistance of structures subjected to impact and blast. In fact, when a structure is stressed by an impulsive load, the energy does not act immediately on all parts; the deformations and stresses caused by the impulsive load propagate through the structure in the form of disturbances like stress and strain waves. The mechanical response of the impacted structure depends strictly on the stress wave propagation because the latter establishes the load distribution over the structure. This is the most evident difference between the so called quasi-static load and the impact load, which must be taken into account by designers for stress analysis under impulsive loads; similarly, it also helps the choice of the proper loading devices and instrumentation used in the impact tests.

The test method should assure high precision of the experimental testing results only when it allows an undoubted resolution of stress wave propagation inside the components of both the testing device and the tested structure. It is scientifically well known that the classic Hopkinson bar [7-10] are developed for the study of the mechanical properties of materials at high strain-rate by strictly controlling and measuring the incident, reflected and transmitted stress wave acting on a specimen. Moreover, the behaviour of
FRC materials under high strain-rate is also currently studied by means of other different experimental apparatus and techniques. Among the most common techniques are the drop-weight test [11, 12], the swinging pendulum, the conventional Charpy impact machines, etc. In the field of the mechanical characterization of materials at high strain-rate, the classical Hopkinson bar has shown distinct advantages and results especially for its capability to measure the wave propagation in materials produced during high strain-rates tests avoiding any filtering of signals, which could potentially cut out important information about the material behaviour. For these reasons, the Hopkinson bar technique is widely used also to determine the mechanical properties of concrete under high loading rates [13-20]. At high strain-rate regime, the experimental technique used for the mechanical characterization of materials strongly influences the results both in the accurateness and in usability. In fact, the precision of the constitutive law in reproducing the actual behaviour of the materials has important consequences in the correctness of design and assessment of concrete structures subjected to impact and blast loading.

In this research program, a MHB [20] has been used. This MHB is installed in the DynaMat laboratory of the University of Applied Sciences of Southern Switzerland (SUPSI) of Lugano (Fig. 3).

The machine consists of two $20 \mathrm{~mm}$ diameter aluminum half-bars (the input and output bar,
Fig. 3 DynaMat laboratory: set-up for the high strain-rate tensile tests

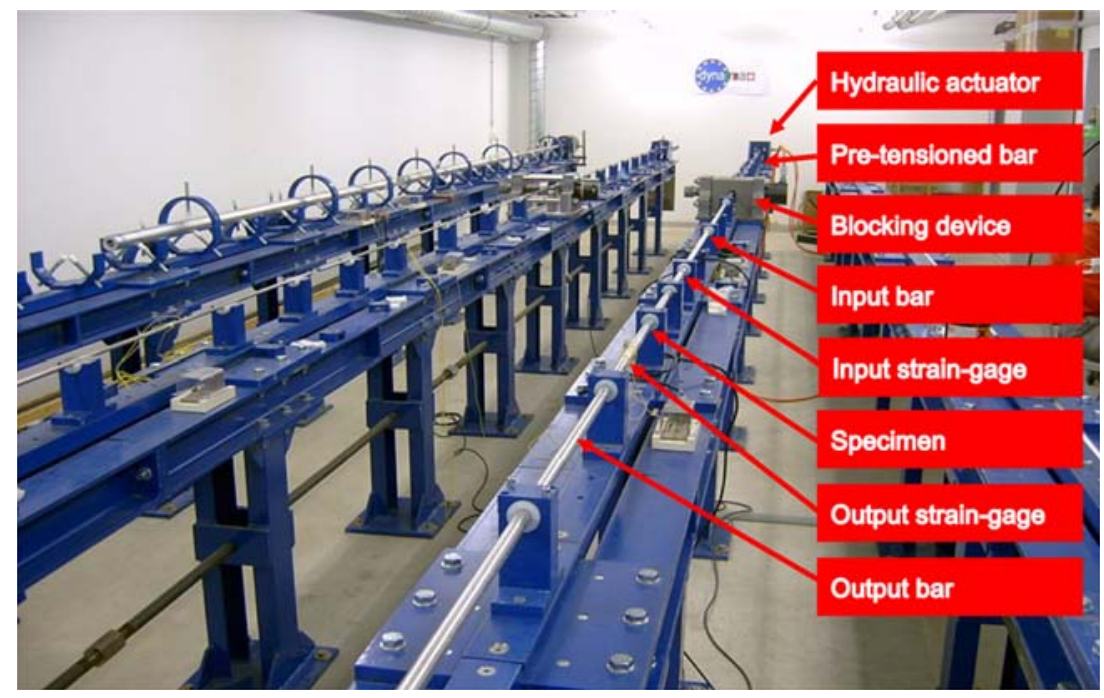


respectively), with the specimen sandwiched in between. By pulling one end (the other is connected with a blocking system) of the high strength steel bar having a length of $6 \mathrm{~m}$ and a diameter of $12 \mathrm{~mm}$ (named pre-tensioned bar), elastic energy is stored in the pre-tensioned bar, which is connected with the incident bar. The diameter of the pre-tensioned bar has been chosen in order to have a better matching of the acoustical impedance with the input bar. By releasing this energy (rupturing the brittle intermediate piece), a rectangular shape wave (with $2 \mathrm{~ms}$ duration) with small rise-time (about $40 \mu \mathrm{s}$ ) is generated and transmitted along the input bar loading the specimen to failure. This is an uniaxial elastic plane stress wave, as the wave-length of the pulse is long compared to the bar transverse dimensions, and the pulse amplitude does not exceed the yield strength of the bar.

The pulse propagates along the input bar with the velocity $C_{0}$ of the elastic wave with its shape remaining constant. When the incident pulse $\left(\varepsilon_{\mathrm{I}}\right)$ reaches the specimen, part of it $\left(\varepsilon_{\mathrm{R}}\right)$ is reflected by the specimen whereas another part $\left(\varepsilon_{\mathrm{T}}\right)$ passes through the specimen propagating into the output bar. The relative amplitudes of the incident, reflected and transmitted pulses, depend on the mechanical properties of the specimen. Straingauges glued on the input and output bars of the

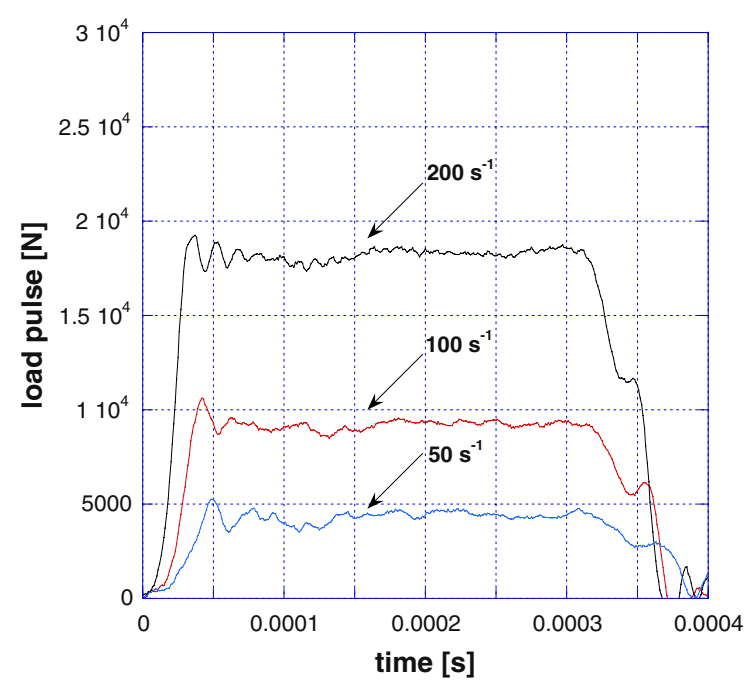

Fig. 4 Not filtered input signals for the three different high strain-rate tensile tests device are used for the measurement of the elastic deformation (as a function of time) created on both half-bars by the incident/reflected and transmitted pulses, respectively.

The different strain-rates were produced by storing elastic energy in the pre-stressed bar length by statically tensioning this bar up to different stress value (lower than its yield strength) that produce the wanted velocity, as shown in Fig. 4 where it can be also observed as the rise time is different for the different velocities.

By using the theory of the elastic wave propagation in bars, and the well substantiated assumption of specimen equilibrium attainment, the stress and strain in the specimen as well as the history of the COD and the strain-rate can be calculated [21]:

$\sigma(t)=E_{0} \frac{A_{0}}{A} \varepsilon_{\mathrm{T}}(t)$
$\varepsilon(t)=-\frac{2 \cdot C_{0}}{L} \int_{0}^{t} \varepsilon_{\mathrm{R}}(t) \mathrm{d} t$

$\operatorname{COD}(t)=-2 \cdot C_{0} \int_{0}^{t} \varepsilon_{\mathrm{R}}(t) \mathrm{d} t$

$\dot{\varepsilon}(t)=-\frac{2 \cdot C_{0}}{L} \varepsilon_{\mathrm{R}}(t)$

where $E_{0}$ is the elastic modulus of the bars; $A_{0}$ their cross-sectional area; $A$ is the specimen cross section area; $L$ is the specimen gauge length; $C_{0}$ is the sound velocity of the bar material; $t$ is time.

These signals are acquired by a transient recorder designed to provide high precision waveform acquisition and analysis capabilities with a maximum $50 \mathrm{MSample} / \mathrm{s}$ real-time sampling rate. The data acquisition system receives the signals from the programmable transducer amplifiers (Fig. 5).

Figure 6 exhibits the signals obtained by the strain-gauge station on input and output bars.

\subsection{Specimen for impact test}

The specimens have been obtained by drilling from cube a core specimen with a diameter of $20 \mathrm{~mm}$ that corresponds to the diameter of the aluminum bars; the specimen is then glued with an epoxy resin (tensile strength $>30 \mathrm{MPa}$ ) to the aluminum bar. Aluminum 
Fig. 5 Logical architecture of measurement acquisition

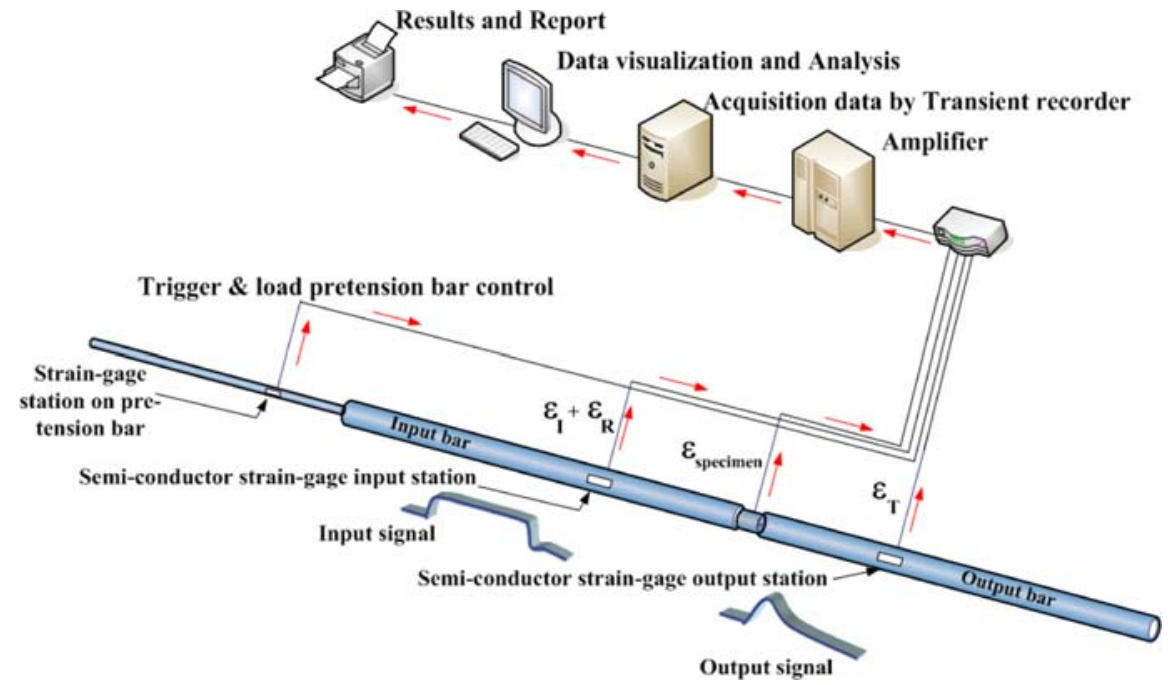

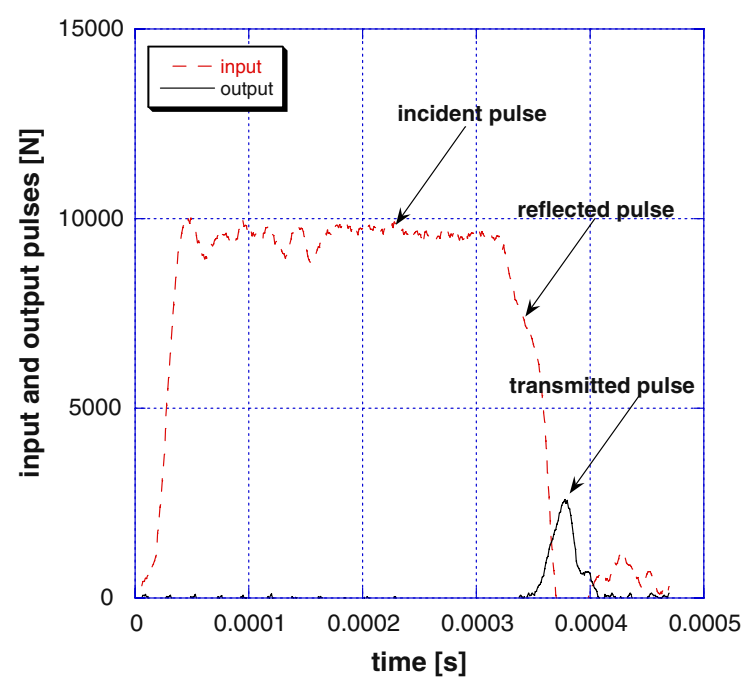

Fig. 6 Not filtered input and output pulse versus time curves of PVA-FRC high strain-rate test

was chosen as the bar material since its acoustical impedance is not far from that of concrete; this minimizes the constraint to transverse deformation of the concrete specimen that depends on the ratio between Poisson and Young modulus. In order to avoid multiple fractures and to focus the analysis to a single fracture, a pre-notch was applied in the specimens so that the section was reduced to $15 \mathrm{~mm}$ in diameter, as shown in Fig. 7.

In order to obtain reference values for the dynamic tests, a series of quasi-static tests were performed in

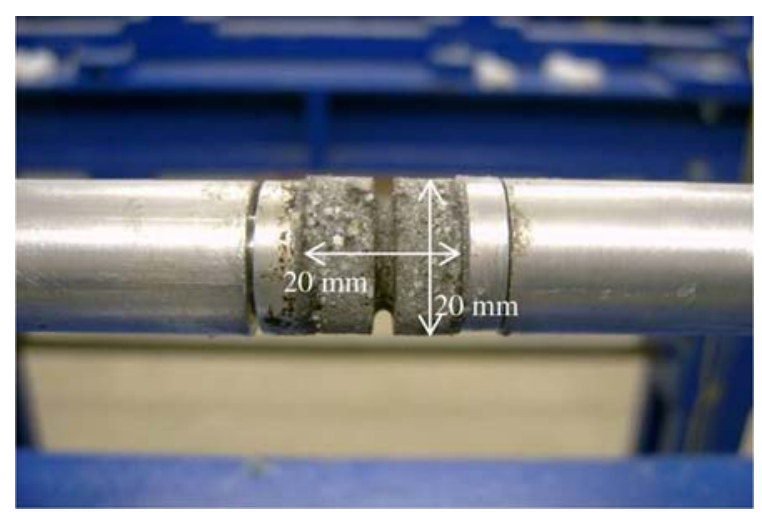

Fig. 7 FRC specimen used in impact tests

an universal machine with a strain-rate of $10^{-4} \mathrm{~s}^{-1}$, as shown in Fig. 8.

\section{Tensile high strain-rate results}

The behaviour under impact loading of steel and PVA FRC has been studied in three different strain-rates: 50, 100 and $200 \mathrm{~s}^{-1}$. The results are collected in Table 2 that reports the average values of tensile strength, fracture energy (obtained by the loaddisplacement curves after the subtraction of the elastic part) and of the strain measured at higher strength.

Figure 9 shows some examples of stress versus time curves for the three strain-rates and the two 


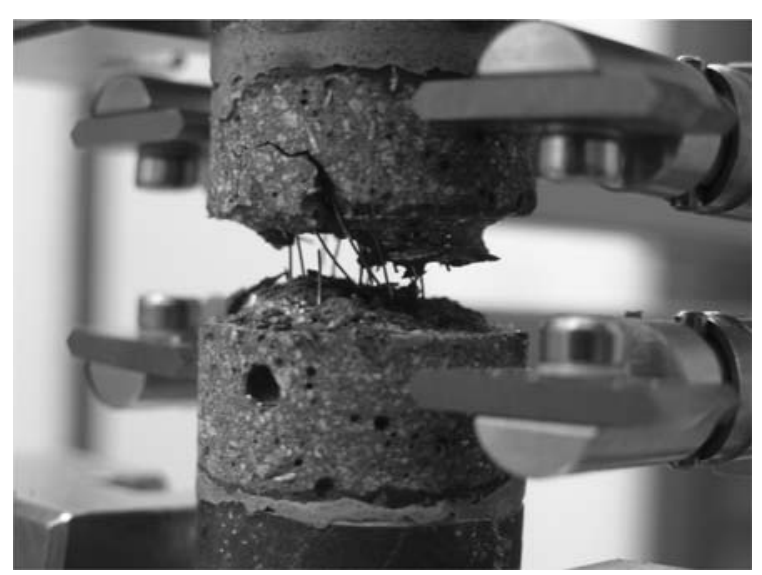

Fig. 8 FRC specimen used in quasi static reference tests after failure

materials. In particular, in Fig. 9a one can observe how the maximum strength is reached for the three strain-rates in different time due to the imposed stainrate. In the case of PVA-FRC, the duration of the fracture process is about 60,100 and $200 \mu$ s for 200 ,
100 and $50 \mathrm{~s}^{-1}$, respectively; while for the S-FRC, for the same strain-rate, it has been obtained 150, 700 and $1300 \mu \mathrm{s}$.

Figure 10 shows the PVA-FRC and S-FRC specimens after the dynamic failure; it can be observed as the steel fibres are pulled-out from the materials (this could originate the difference in terms of fracture energy), while the majority of PVA fibres were subjected to tensile failure.

In Fig. 11 the stress versus COD curves of the same tests at the three strain-rates are shown, while in Fig. 12 all experimental curves are reported (note that the COD scales for the PVA fibre is larger than that of the steel fibre).

As already observed in recent experimental studies on the compressive behaviour of S-FRC at 20 and $100 \mathrm{~s}^{-1}$ [22], where it was pointed out that at higher strain rates the post-peak ductility is absent, also in tension tests this post-peak ductility seems to disappear. It should be considered that, in these tests, only one section is tested and the pull-out process is frictional and not much sensitive to rate.

Table 2 High strain-rate results

\begin{tabular}{llllccc}
\hline & \multicolumn{2}{l}{ Materials } & & & \\
\cline { 2 - 7 } & PVA-FRC & S-FRC & PVA-FRC & S-FRC & PVA-FRC & S-FRC \\
\hline Strain-rate $\left(\mathrm{s}^{-1}\right)$ & \multicolumn{2}{c}{50} & & 100 & 200 \\
Tensile strength $(\mathrm{MPa})$ & $11.4 \pm 3.4$ & $12.0 \pm 3.2$ & $13.9 \pm 2.8$ & $12.5 \pm 5.2$ & $12.7 \pm 2.3$ & $16.0 \pm 6.8$ \\
Fracture energy $\left(\mathrm{J} / \mathrm{m}^{2}\right)$ & $682 \pm 74$ & $11638 \pm 4597$ & $558 \pm 165$ & $6672 \pm 1836$ & $417 \pm 65$ & $6915 \pm 1030$ \\
Ultimate strain $(\mu \varepsilon)$ & $921 \pm 505$ & $3603 \pm 1952$ & $820 \pm 328$ & $3404 \pm 2516$ & $630 \pm 378$ & $2700 \pm 993$ \\
\hline
\end{tabular}

Fig. 9 Stress versus time curves for three strain-rates: a PVA-FRC; b S-FRC (a)

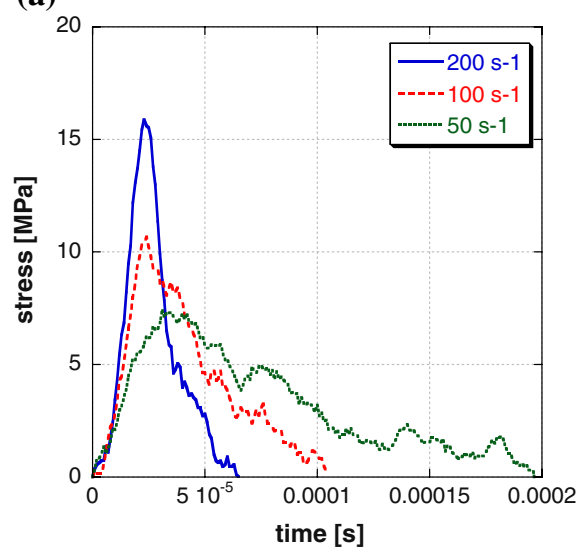

(b)

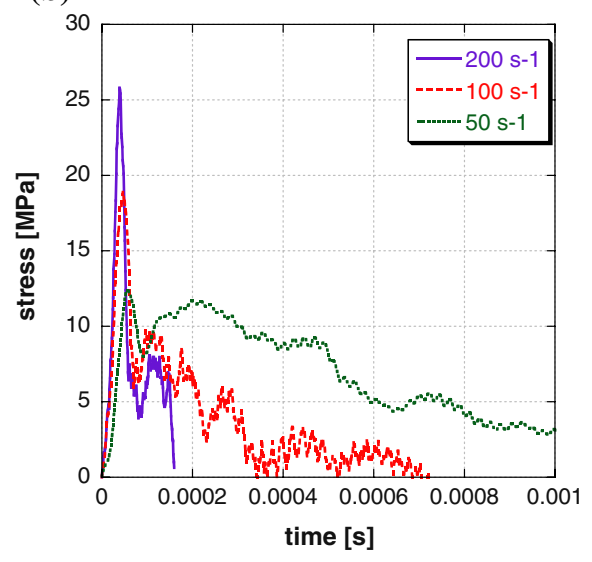


Fig. 10 PVA-FRC (a) and S-FRC (b) specimens after impact tests
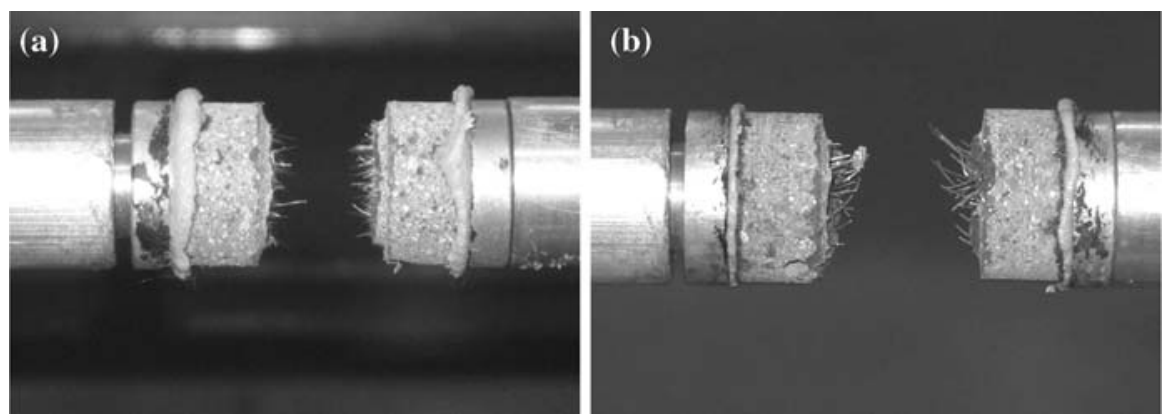

(a)

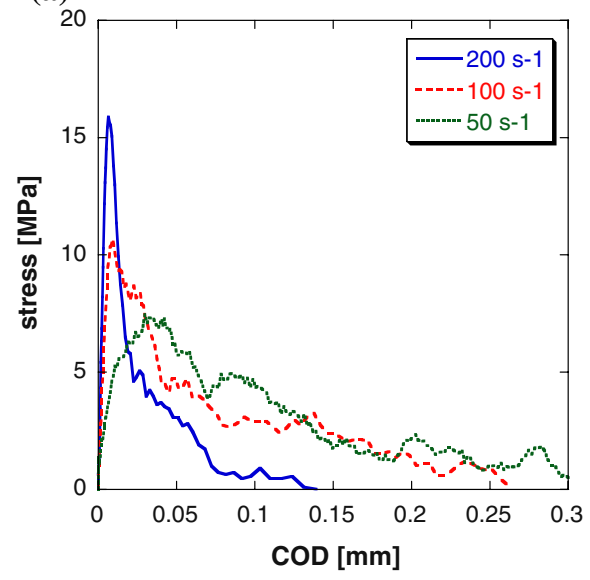

(b)

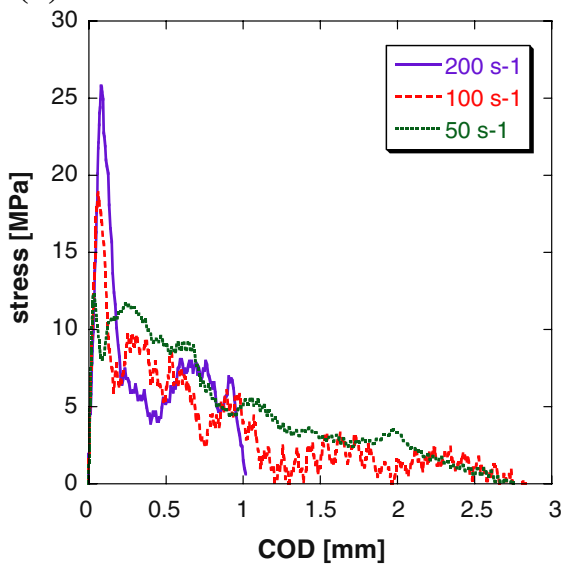

Fig. 11 Stress versus
CTOD curves for three different strain-rates: a PVA-FRC; b S-FRC
For the PVA-FRC one can observe a decrease of fracture energy that indicates an embrittlement of the composite materials. The tensile strength of the S-FRC increases with the strain-rate while the tensile strength of PVA-FRC seems to be less sensitive to the strain-rates even though it remarkably increases with respect to the static values.

In order to better evidence the strength enhancement of S-FRC, Fig. 13 shows the trend of the dynamic increase factor (DIF), that is the ratio between the dynamic and static strength, with the strain-rate increase.

\section{Discussion}

The previous considerations aim to open a debate on several aspects concerning the experimental behaviour of FRC. In general the first question is: "how to measure the high strain-rate FRC behaviour?", "what techniques?", "what specimen (geometry, dimension, etc.)?" and, last but not least, "how to measure the high strain rate FRC structures behaviour?"

\subsection{Strain-rate of FRC}

A specification is necessary about the strain-rate obtained during dynamic tests with a Hopkinson bar where the strain-rate is not constant because of the loading process. For the metallic or ductile materials, where the plastic zone is well defined, the stainrate is obtained as an average of the strain-rate value along the abovementioned zone. For the cementitious materials, or in the general case of brittle materials, the strain-rate has been measured when the maximum value of the strength is reached [21]. Figure 14 shows the comparison between the strainrate and the stress versus time, where it is easy to observe the strain-rate obtained for the impact test (in this case is $65 \mathrm{~s}^{-1}$ ). When considering other experimental techniques, how the strain-rate is measured? 
Fig. 12 Stress versus COD curves for S-FRC and PVAFRC, respectively, at $200 \mathrm{~s}^{-1}$ (a), $100 \mathrm{~s}^{-1}$ (b), and $50 \mathrm{~s}^{-1}(\mathbf{c})$ (a)
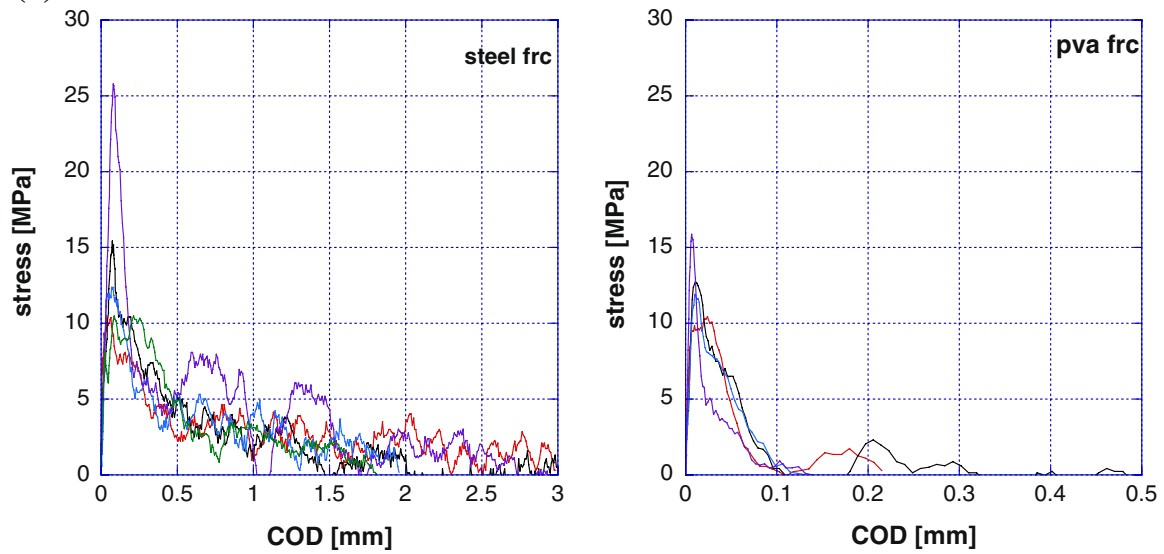

(b)
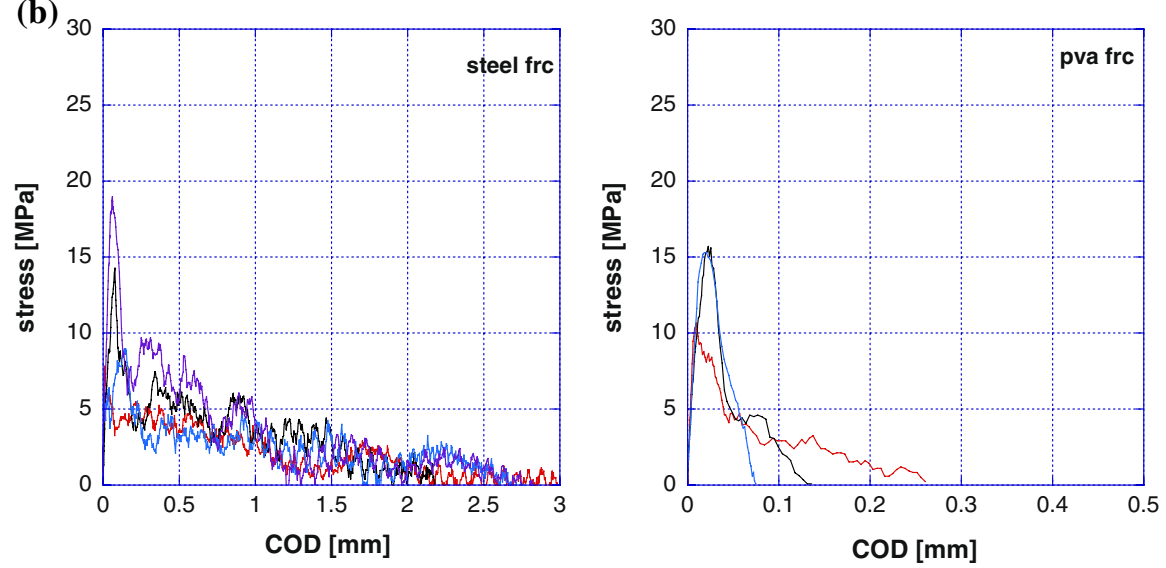

(c)

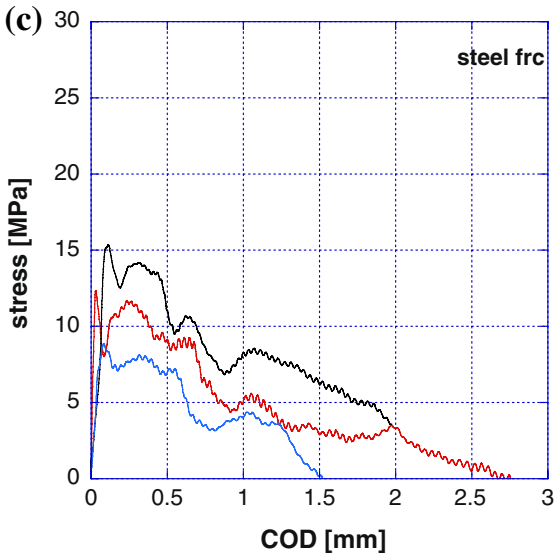

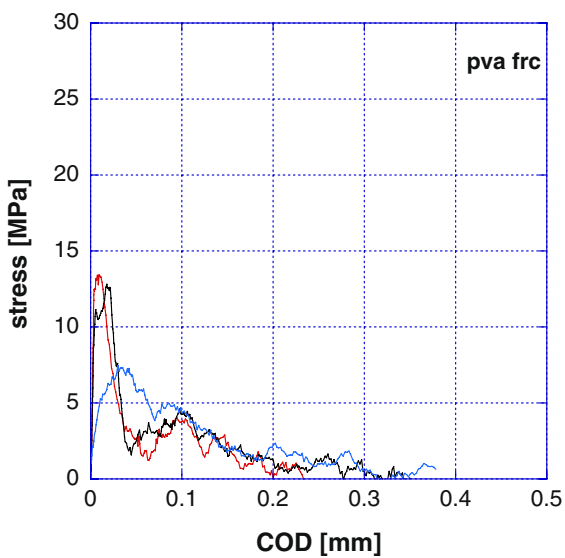

\subsection{Dimension and type of the specimen}

The high strain-rate tests needs small specimen in order to reach higher velocity but this is in contrast with the representative volume of materials. As a results, it is necessary to define the shape and dimensions of the FRC specimen, and if a notch is required or not [23]. 


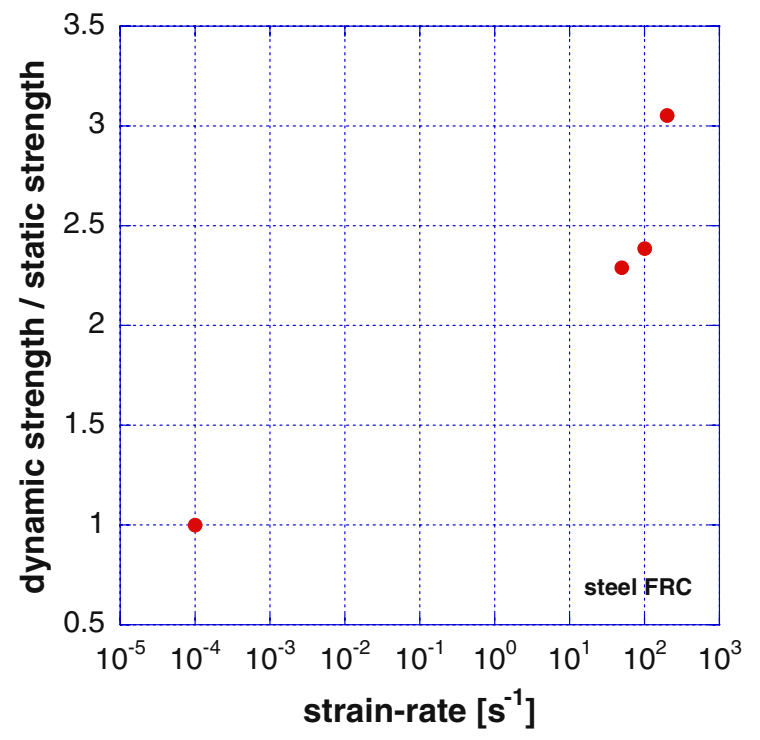

Fig. 13 Dynamic increase factor versus strain-rate for the S-FRC

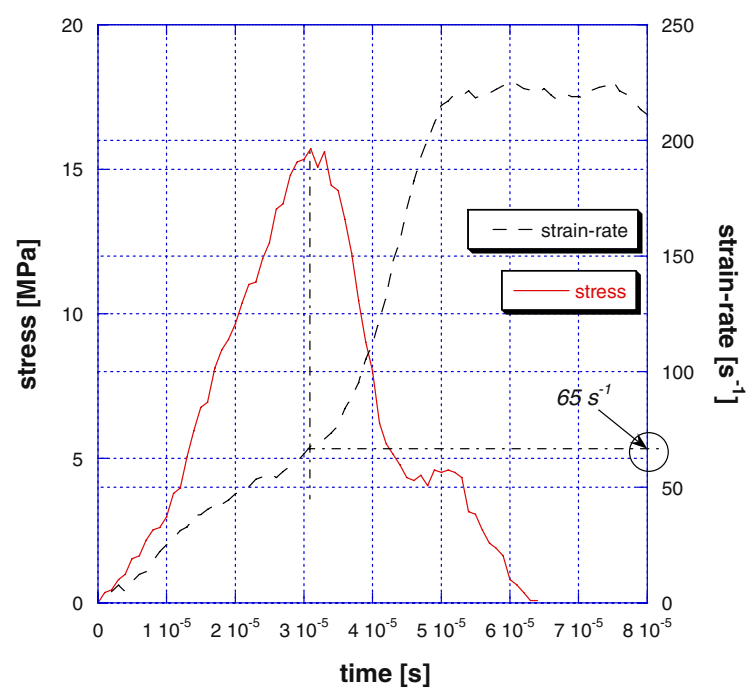

Fig. 14 Strain-rate and stress versus time curves of high strain-rate test

\subsection{Type of fibre}

From these preliminary tests on FRC specimens, different failure modes can be observed. In fact, in the S-FRC specimens the fibres were pulled out, while in the PVA-FRC specimens a large number of PVA fibres were subjected to tensile failure (Fig. 15). On the basis of the experimental results presented above, when steel fibres are used, the dynamic response after cracking is softening (brittle), while it results hardening under static loads. Therefore, although the fracture energy remarkably increases with the strain-rate, a question rise up: "are the usual fibres suitable for impact and blast loadings?" The answer could suggest the development of new types of fibres in which a nano-indentation is developed to increase their pull-out resistance.

\section{Concluding remarks}

Fracture behaviour of high performance of concrete reinforced with steel and PVA micro-fibres, under static and impact loading, is presented.

FRC specimens were made of a concrete matrix having a high strength and a high volume fraction (2.5\%) of steel or PVA fibres.

Uniaxial tensile tests on notched and un-notched specimens, as well as bending tests on small notched beams having the same fracture area of the specimens for the uniaxial tests, were performed to study the static behaviour of FRC by using different specimen geometries and different strain gradients in the fracture area. Experimental results from the whole set of tests show that toughness provided by steel fibres is significantly (about ten times) higher that that provided by PVA fibres.

Impact tests were performed by using a MHB. Experimental results show that the ratio between the dynamic and static strength (DIF) remarkably increases with the strain-rate but that the materials become more brittle; this underlines the need of further research towards new fibres and new matrices for optimizing the material response at high strain rates.

However, FRC is a composite material that requires a proper mix design where all the components should be properly proportioned for a specific application. As a consequence, a proper matrix for steel fibres is generally different than that for synthetic fibres; this underlines that a comparison between different fibres in the same concrete mix may not be completely satisfactory because the optimum matrix for steel fibres may not be the best one for PVA fibres (or vice versa). Beside the lower performance of the fibre itself, the latter could be a possible explanation of the lower performance of PVA fibres, as evidenced in the experimental results 
Fig. 15 Photo of the fracture surface of the PVA-FRC (a) and S-FRC specimen (b)
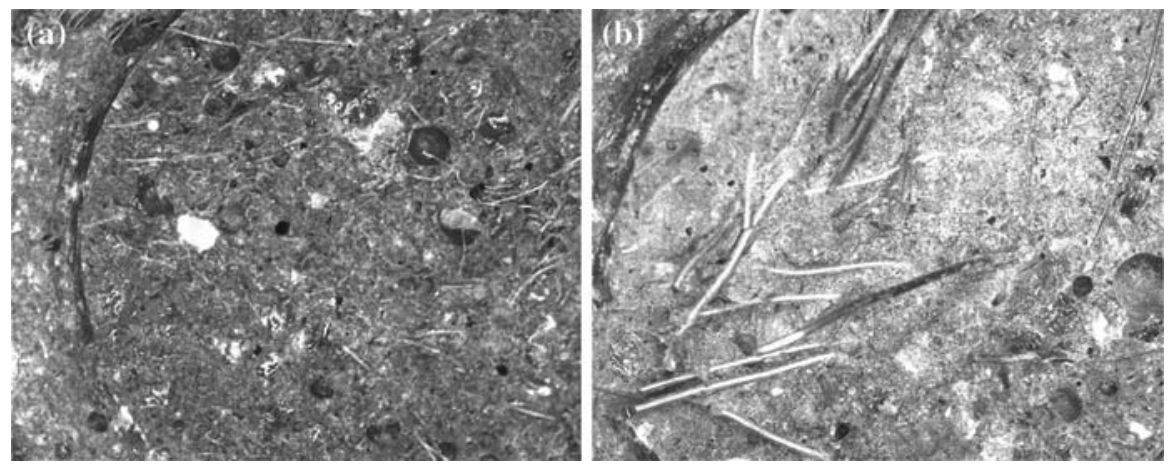

presented in this paper; a meaningful comparison should be performed between the same volume fraction of fibres included in properly designed concrete matrices.

\section{References}

1. di Prisco M, Felicetti R, Plizzari GA (eds) (2004) Proceedings of the 6th RILEM symposium on fibre reinforced concretes (FRC). BEFIB 2004, RILEM PRO 39, 1514 pp

2. Bindiganavile V, Banthia N (2005) Generating dynamic crack growth resistance curves for fiber reinforced concrete. Exp Mech 45(2):112-122

3. Ahmad A, di Prisco M, Meyer C, Plizzari GA, Shah S (eds) (2004) Proceedings of the international workshop fiber reinforced concrete: from theory to practice, Bergamo, 24 25 September 2004, Starrylink, $222 \mathrm{pp}$

4. Bindiganavile V, Banthia N (2005) Impact response of the fiber-matrix bond in concrete. Can J Civ Eng 32(5):924933

5. Carpinteri A, Gambarova P, Ferro G, Plizzari GA (eds) (2007) Proceedings of the 6th international conference on fracture mechanics of concrete and concrete structures, vol 3, FraMCoS 6, Catania, 18-21 June, Balkema, 1886 pp

6. Sorelli L, Meda A, Plizzari GA (2005) Bending and uniaxial tensile tests on concrete reinforced with hybrid steel fibers. ASCE Mater J Struct Eng 15(5):519-527

7. Hopkinson B (1914) A method of measuring the pressure produced in the detonation of high explosives or by the impact of bullets. Phil Trans Royal Soc Lond A 213:437456

8. Kolsky H (1949) An investigation of the mechanical properties of materials at very high rates of loading. Proc Phys Soc Lond B 62:676-700

9. Davies RM (1948) A critical study of the Hopkinson pressure bar. Phil Trans R Soc Lond A 240:375-457

10. Bindiganavile V, Banthia N, Aarup B (2002) Impact response of ultra-high strength fiber reinforced cement composite. ACI Mater J 99(6):543-548
11. Banthia N, Mindess S, Bentur A, Pigeon M (1989) Impact testing of concrete using a drop weight impact machine. Exp Mech 29(1):63-69

12. Albertini C, Cadoni E, Labibes K (1996) Dynamic mechanical behaviour of large concrete specimens by means of a bundle Hopkinson bar. In: Proceedings of 2nd international symposium on impact engineering. Chinese Mechanics Journal, Beijing, pp 214-219

13. Albertini C, Cadoni E, Labibes K (1999) Study of the mechanical properties of plain concrete under dynamic loading. Exp Mech 39(2):137-141

14. Cadoni E, Labibes K, Berra M, Giangrasso M, Albertini C (2000) High strain-rate tensile concrete behaviour. Mag Concr Res 52(5):365-370

15. Körmeling HA, Zielinski AJ, Reinhardt HW (1980) Experiments on concrete under single and repeated uniaxial impact tensile loading. Stevin Report 5-80-3, Delft

16. Reinhardt HW (1982) Concrete under impact loading tensile strength and bond. HERON 27(3):4-47

17. Reinhardt HW, Rossi P, Van Mier JGM (1990) Joint investigation of concrete at high rates of loading. Mater Struct 23(90):213-216

18. Rossi P, Van Mier JGM, Boulay C, Le Maou F (1992) The dynamic behaviour of concrete: influence of free water. Mater Struct 25(92):509-5141

19. Albertini C (2005) The material testing at medium and high strain-rate with the hydro-pneumatic machine and the modified Hopkinson bar of Joint Research Centre technology. Technology Transfer Report (in force of the licensing agreement with JRC No 18527-2001-10 T1SC ISP IT)

20. Albertini C, Montagnani M (1974) Testing techniques based on the split Hopkinson bar. In: The mechanical properties at high strain-rates. Institute of Physics Conference Series No 21, pp 22-32

21. Cadoni E et al (1997) Mechanical response in tension of plain concrete in a large range of strain-rates. Technical Note No. I.97.194, Joint Research Centre, $150 \mathrm{pp}$

22. Lok TS, Zhao PJ (2004) Impact response of steel fiberreinforced concrete using a split Hopkinson pressure bar. J Mat Civ Eng 16(1):54-59

23. Bindiganavile V, Banthia N (2006) Size effects and the dynamic response of plain concrete. ASCE J Mater Civ Eng 18(4):485-491 